Perfil: Arquitecto Nelson Brown, primer decano de la Facultad de Arquitectura / Parés, Javier (jp_nica68@yahoo.com )

\section{Arquitecto Nelson Brown, pri- mer decano de la Facultad de Arquitectura}

\author{
MSc. Arq. Javier Parés / \\ Secretario FARQ/ \\ jp_nica68@yahoo.com
}

El arquitecto Nelson Bronw nació en Boaco, Nicaragua, el 15 de Octubre de 1950. Arquitecto graduado de 1968 -1976. Especialista en Restauración edilicia y Centros históricos / antiguos en Universidad de Florencia. Italia.1978 - 1979.

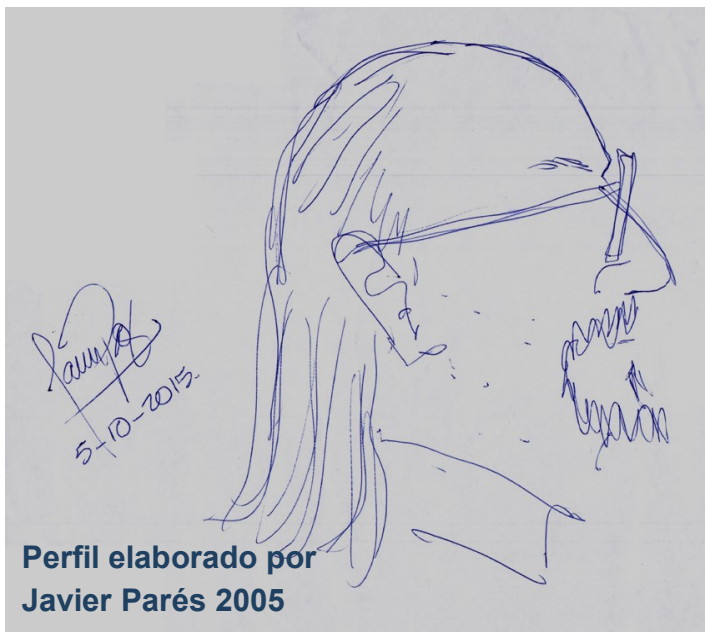

Al mismo tiempo el arquitecto desarrollaba el ejercicio profesional, desde su empresa de diseño y construcción "Brown y Arquitectos"' en donde también fue guía de muchos nóveles estudiantes de arquitectura quienes fueron sus dibujantes y asistentes como una simbiosis de la academia y la práctica real.

Recuerdo que cuando fui su asistente, llegaba todas las mañanas donde estábamos el equipo de dibujante, mesa por mesa revisando los avances, y al terminar solía decir una frase muy válida aún hoy "puta mano, ustedes me deberían estar pagando a mi por todo lo que están aprendiendo conmigo"'. Era una persona con una visión profesional y a la vez revolucionaría.

Entre todas sus obras, me identifico con él especialmente en su proyecto del 'Parque de la Paz' por su significado de integración social para con los managuas los fines de semana en este sitio. La utilización del faro, el anfiteatro, el redondel, la cascada, etc., destinados para conciertos al aire libre, y hacer auténticas áreas de esparcimiento para la gente.

Lamentablemente los gobiernos municipales poco a poco fueron olvidándolo y hoy día su significado ha cambiado.

Nelson tiene su marca formal en la utilización de líneas curvas (a veces el paraboloide hiperbólico) y uso de tragaluces, iluminación y ventilación cenital. Hay que destacar su aporte al innovar en el uso de estas formas, armonizando con los nuevos materiales que empezaron a integrarse al mercado a partir de los 90 .
Director de la Escuela de Arquitectura - Universidad Nacional de Ingeniería (1986 - 90). Fue el primer decano de la Facultad de Arquitectura (1990 - 95) y participó en el proceso de transformación de EscuelaFacultad en 1990.

Además de ser el decano de la carrera, fue profesor de diseño, especialmente en los últimos años de la carrera (los proyectos 7, 8 y 9). Se caracterizó por enseñar con la práctica, con evidencias más que teorizar el proceso de diseño.

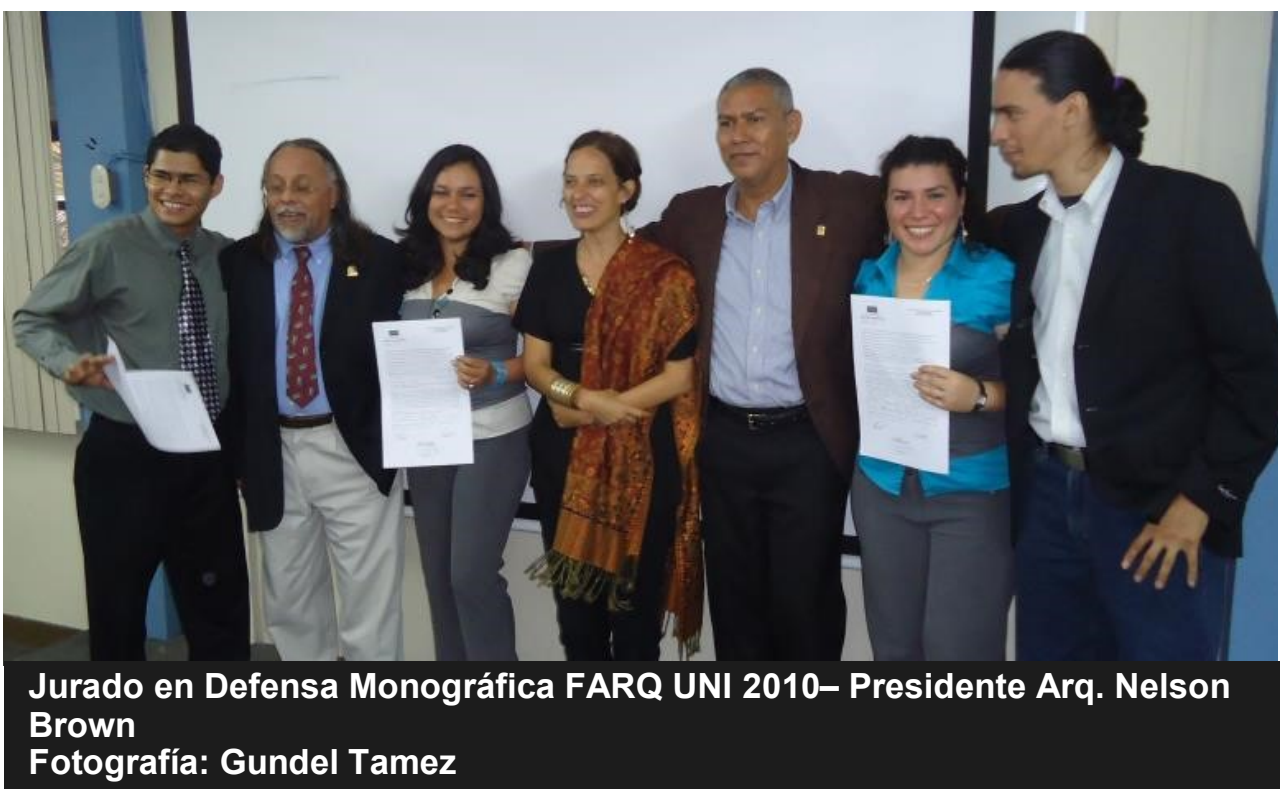


Perfil: Arquitecto Nelson Brown, primer decano de la Facultad de Arquitectura / Parés, Javier (jp_nica68@yahoo.com )

\section{Otros Cargos}

- Director de Ordenamiento Territorial. Dirección de Planificación Física y miembro del Estudio Marco Nacional de Referencia para la Planificación Física. Instituto Nicaragüense de Estudios Territoriales. INETER. MNRFP. 1982-84

- $\quad$ Profesor Titular - Universidad Nacional de Ingeniería (UNI) 1983 -2005 .

\section{Algunos de sus proyectos construidos}

- Oficinas administrativas del Gobierno Regional. San Carlos. Río San Juan/1981.

- Parque de la Paz. Presidencia de la República. Concurso Nacional/1994. Demolido en 2014.

- Urbanización BOSQUES DEL MAR. San Juan del Sur/1999.

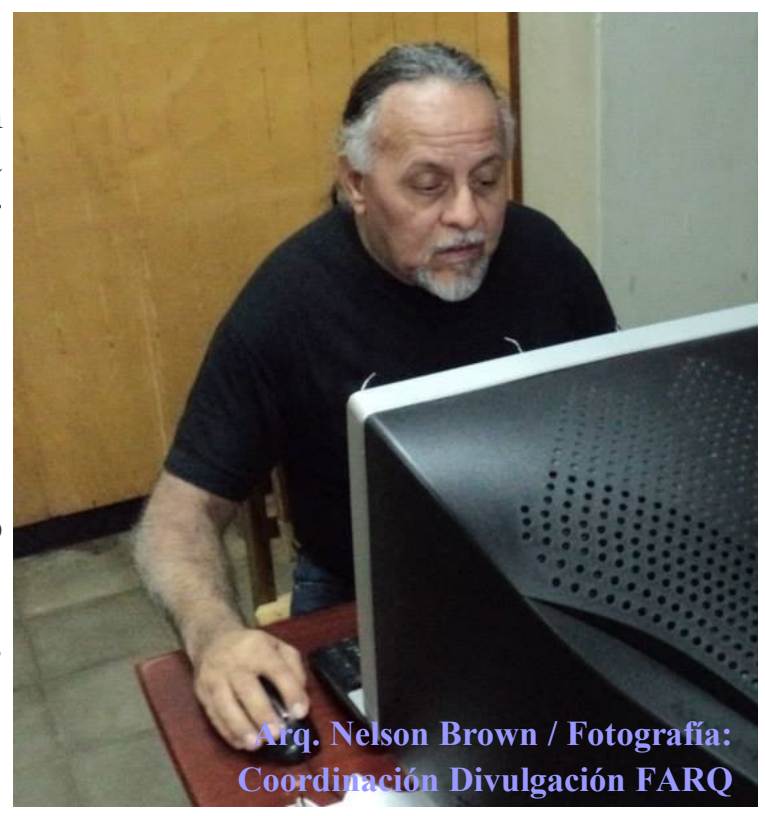

- Edificio del Centro de Información para la Prevención de los Desastres Naturales. INETER/2000.

- Edificio de las Comisiones Parlamentarias de la Asamblea Nacional/2005.
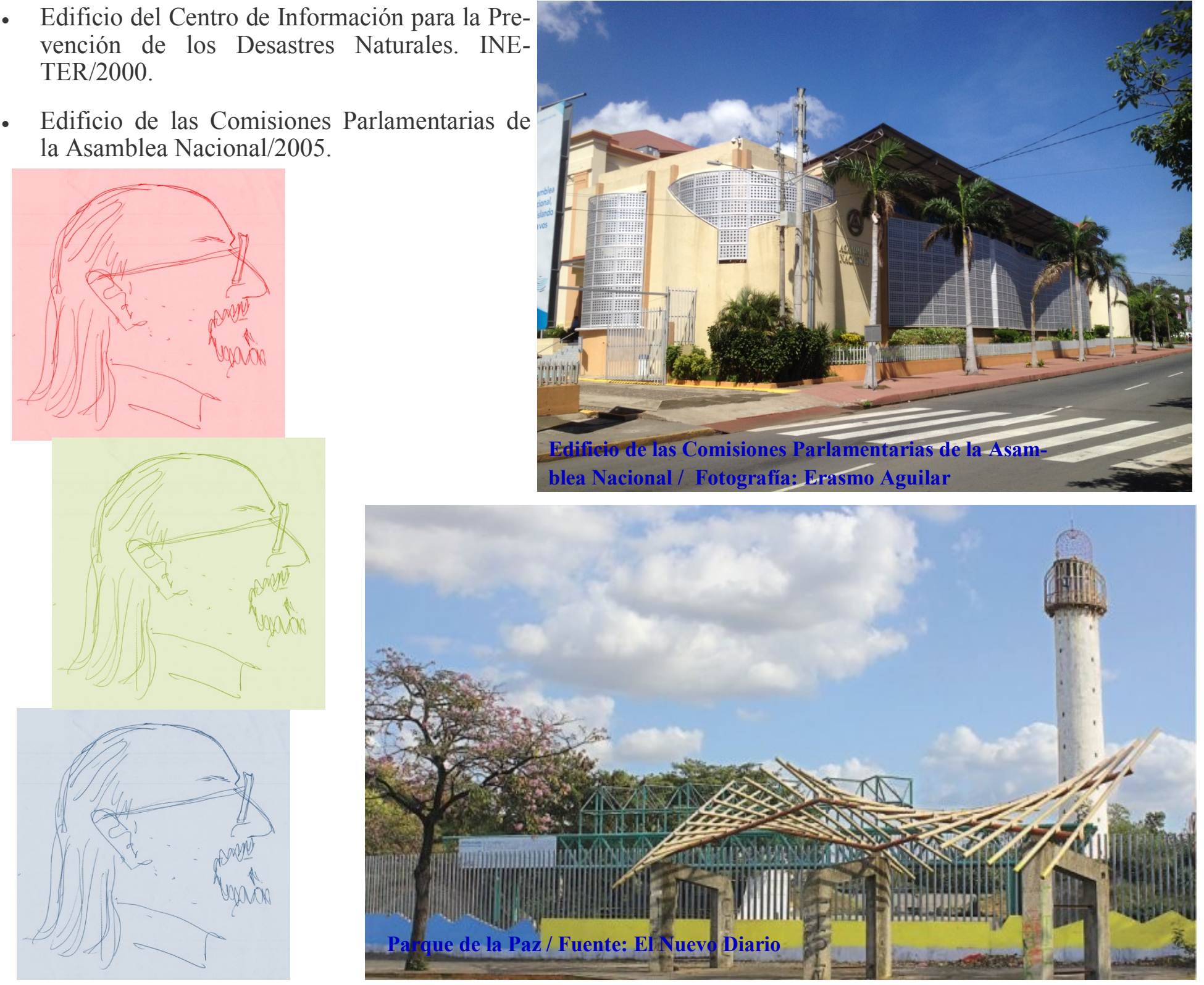